\title{
Prenatal dehydration alters renin-angiotensin system associated with angiotensin-increased blood pressure in young offspring
}

\author{
Junchang Guan ${ }^{1,2,5}$, Caiping Mao ${ }^{1,5}$, Feichao Xu${ }^{1}$, Chunsong Geng ${ }^{1}$, Liyan Zhu ${ }^{1}$, Aiqing Wang ${ }^{1}$ \\ and Zhice $\mathrm{Xu}^{1,3,4}$
}

The renin-angiotensin system (RAS) has an important role in cardiovascular homeostasis. This study determined the influence of water deprivation during pregnancy on the development of the RAS in rats, and examined blood pressure (BP) in the adolescent offspring. Pregnant rats were water deprived for $\mathbf{3}$ days at late gestation, and we examined fetal cardiac ultrastructure, as well as heart angiotensin (Ang) II receptor protein and mRNA, liver angiotensinogen and plasma Ang II concentrations. We also tested cardiovascular responses to i.v. Ang II in the young offspring. In utero exposure to maternal water deprivation significantly decreased fetal body and heart weight, and increased fetal plasma sodium and osmolality. Fetal liver angiotensinogen mRNA, plasma Ang I and Ang II concentrations were also increased. Although fetal $A T_{1 \mathrm{a}}$ and $A \mathrm{~T}_{1 \mathrm{~b}}$ receptor $\mathrm{mRNA}$ and $A \mathrm{~T}_{1}$ protein were not changed, $\mathrm{AT}_{2}$ receptor $\mathrm{mRNA}$ and protein levels in the heart were significantly increased following maternal dehydration. Prenatal exposure to maternal water deprivation had no effect on baseline BP; however, it significantly increased BP in response to i.v. Ang II infusion, and decreased baroreflex sensitivity in the offspring. In addition, the heart $\mathrm{AT}_{2}$ receptor mRNA and protein were higher in the offspring exposed to prenatal dehydration. The results of this study demonstrate that prenatal dehydration affected the RAS development associated with an Ang II-increased BP in fetal origin.

Hypertension Research (2009) 32, 1104-1111; doi:10.1038/hr.2009.155; published online 25 September 2009

Keywords: water deprivation; fetal $\mathrm{AT}_{1}$ and $\mathrm{AT}_{2}$ receptor; baroreflex; fetal heart

\section{INTRODUCTION}

The renin-angiotensin system (RAS) is composed of several key elements, including hepatic-derived angiotensinogen, renal enzyme renin and physiologically active peptide angiotensin (Ang) II. $^{1}$ The RAS has an important role in cardiovascular homeostasis. ${ }^{2}$ Women may face mild-to-severe dehydration during pregnancy due to vomiting, diarrhea and certain diseases. Water deprivation can cause imbalance in body fluids, ${ }^{3}$ and intracellular and extracellular dehydration. ${ }^{4} \mathrm{~A}$ number of studies ${ }^{5-7}$ suggest that water deprivation can reduce blood volume and increase plasma sodium and osmolality, leading to a series of responses in the RAS, including increased plasma renin activity ${ }^{5-8}$ and Ang II concentrations. ${ }^{8,9}$ All those data were from adult studies, however, the influence of prenatal water deprivation on the development of the fetal RAS is largely unknown.

A body of epidemiological and experimental evidence shows that intrauterine insults may program cardiovascular diseases such as hypertension in late life. ${ }^{10-16}$ Previous studies ${ }^{17-19}$ have suggested that the RAS may have a critical role in the development of hypertension by intrauterine problems during the fetal development.
In this study, we examined fetal body fluid balance under the condition of maternal dehydration, determined the RAS and cardiac Ang receptors in the fetus and offspring following maternal dehydration and tested blood pressure (BP) in the young offspring. The information achieved contributes to further understanding the development of cardiovascular diseases of fetal origin.

\section{METHODS}

Animals

Experiments were performed on Sprague-Dawley rats housed in a controlled environment of $22-25^{\circ} \mathrm{C}$ and a 12 -h light-dark cycle. Pregnant rats were randomly divided into two groups: control group and water-deprived group (WD, water bottle removed during deprived period) ( $n=5-6$ per each group). In the control group, pregnant rats were provided both water and food. In the WD group, animals were deprived of water for 3 days from day 18 of gestation, whereas food was provided (water deprivation for 3 days in rodents has been reported frequently). ${ }^{20,21}$

On day 21 of gestation, maternal rats were anesthetized with sodium pentobarbital ( $20 \mathrm{mg} \mathrm{kg}^{-1}$, intraperitoneally). A small cut was made at the middle of abdomen of rats and fetuses were removed for ultrastructural analysis

${ }^{1}$ Perinatal Biology Center, Soochow University First Affiliated Hospital, Suzhou, China; ${ }^{2}$ Department of Microbiology, Bengbu Medical College, Bengbu, Anhui, China; ${ }^{3}$ Nanjing University School of Medicine, Nanjing, China and ${ }^{4}$ Center for Perinatal Biology, Loma Linda University, Loma linda, CA, USA

${ }^{5}$ These authors contributed equally to this work and Institutes 1,2 and 3 contributed equally to this work.

Correspondence: Dr Z Xu, Perinatal Biology Center, Soochow University First Affiliated Hospital, 199 Renai Road, Suzhou, China.

E-mail: xuzhice@suda.edu.cn

Received 2 April 2009; revised 16 July 2009; accepted 13 August 2009; published online 25 September 2009 
of the fetal heart. Fetal heart and body length were measured (two fetuses from the same dam as $n=1$ ). The apical area of fetal heart was sliced (1-mm cubes each) for electromicroscopy. The sliced tissue samples were fixed in $0.05 \mathrm{M}$ phosphate buffer, $\mathrm{pH} 7.2$, containing $2.5 \%$ glutaraldehyde, washed in phosphate buffer, and post-fixed in $1 \%$ osmium tetroxide. After dehydration in graded alcohols, the tissue was put through propylene oxide and embedded in Epoxy resin. Blocks were sectioned and stained with toluidine blue and examined by a light microscope. Selected areas were sectioned using an LKB ultramicrotome (up to $1 \mu \mathrm{m}$; Leica Reuchert Ultracuts, Vienna, Austria), and sections were double stained with uranyl acetate and lead citrate, and examined with a Philips 300 electron microscope (model H2600, Philips, Bejing, China).

Blood samples ( $6-7$ fetuses from the same dam as $n=1$ ) were collected for determination of blood values and plasma hormones. The fetal heart and liver tissue was immediately collected and prepared for measuring mRNA and protein of $\mathrm{AT}_{1} \mathrm{R}$ and $\mathrm{AT}_{2} \mathrm{R}$, and angiotensinogen.

For offspring experiments, pregnant rats were given water following 3-day water deprivation, as described above. They were allowed to give birth naturally. Pups were kept with their mothers until weaning. At weaning, male pups were separated and transferred to cages (two per cage). The male adolescent offspring at 7-8 weeks of age were used for cardiovascular and molecular studies. The investigation in this work conformed to the Guide for the Care and Use of Laboratory Animals published by the US NIH, and all procedures were approved by the Institute Animal Care Service.

\section{Fetal weight and length}

Fetal body length (from crown to rump) and tail length were measured. Fetal body, heart and placenta were weighted. Then fetal body, heart and placental tissue were dried in an oven at $65^{\circ} \mathrm{C}$ for $24 \mathrm{~h}$ to remove water. Dried fetal body, heart and placenta were weighed.

\section{Measurement of blood values}

Water deprivation was selected at late gestation, as fetal blood collection is only possible during that period. Maternal and fetal blood samples were collected into ice-cold tubes. ${ }^{22}$ Fetal blood samples were collected directly from the heart using intracardiac puncture, and fetal blood was pooled together in the same litter ( $n=6-7$, each group). Blood $\mathrm{pH}$, oxygen saturation, sodium concentrations and hematocrit were determined with a Nova analyzer (Nova Biochemical, Model pHOx Plus L, Waltham, MA, USA). The remaining blood was centrifuged at $4{ }^{\circ} \mathrm{C}$ for $15 \mathrm{~min}$. Then plasma was used for measuring osmolality with an advanced digmatic osmometer (model 3MO, Advanced Instruments, Needlham Heights, MA, USA), and the remaining plasma was kept at $-70{ }^{\circ} \mathrm{C}$ for determinations of hormones.

\section{Radioimmunoassay for plasma Ang I and Ang II}

Plasma Ang I and Ang II concentrations were measured by radioimmunoassay with a commercial kit (Diagnostic Products, Shanghai, China). The sensitivity of each assay was $10 \mathrm{pg} \mathrm{ml}^{-1}$ and $0.1 \mathrm{ng} \mathrm{ml}^{-1}$, respectively. The intra- and interassay variations were 4 and $5 \%$. The data were treated in a blind manner.
Real-time PCR for angiotensinogen, $\mathrm{AT}_{1 \mathrm{a}} \mathrm{R}, \mathrm{AT}_{1 \mathrm{~b}} \mathrm{R}$ and $\mathrm{AT}_{2} \mathrm{R}$ mRNA The rat primers were designed on the basis of the published rat genomic sequences in GenBank (Table 1). Purification of total RNA from the liver and heart tissue was performed using a protocol adapted from published methods. ${ }^{23}$ The tissue was homogenized in TRIZOL (Invitrogen, Carlsbad, CA, USA). RNA was then immediately isolated, precipitated, washed, and stored in $75 \%$ ethanol at $-70^{\circ} \mathrm{C}$. RNA was only used if the ratio between spectrophotometer readings $(260 \mathrm{~nm}: 280 \mathrm{~nm})$ was between 1.8 and 2.0. Samples were digested with DNase I to degrade any DNA present in the RNA isolation. A reverse transcription and first strand cDNA synthesis was performed using MMLV-RT reverse transcriptase (Invitrogen). The first strand cDNA was checked using the housekeeping gene to assess the quality of the reverse transcription.

Real-time PCR (BIO-Rad icycler iQ, Hercules, CA, USA) was performed in a 96-well plate using $12.5 \mu \mathrm{l} 2 \times$ SYBR Green master mix (Takara, Otsu, Japan). Amplification conditions involved a pre-incubation at $95^{\circ} \mathrm{C}$ for $1 \mathrm{~min}$ followed by amplification of the target DNA for 45 cycles $\left(95^{\circ} \mathrm{C}\right.$ for $10 \mathrm{~s}$ and $60^{\circ} \mathrm{C}$ for $20 \mathrm{~s}$ ), and the fluorescence collection at $60^{\circ} \mathrm{C}$. Melting curve analysis was performed at a linear temperature transition rate of $0.5^{\circ} \mathrm{C} \mathrm{s}^{-1}$ from 65 to $95^{\circ} \mathrm{C}$ with continuous fluorescence acquisition. All experiments were repeated three times for reproducibility. The relative gene expression (RGE) was normalized to GAPDH and calculated as the following: $\mathrm{RGE}=2^{-\left(T \Delta C_{\mathrm{t}} N \Delta C_{\mathrm{t}}\right)}$, where $T$ represents the level of experimental groups, $N$ represents the control group whose expression level was calculated, and $\Delta C_{\mathrm{t}}$ is the difference of threshold cycle $\left(C_{t}\right)$ between the gene of interest and GAPDH. ${ }^{24}$

\section{Western blot analysis for $\mathrm{AT}_{1} \mathrm{R}$ and $\mathrm{AT}_{2} \mathrm{R}$}

Fetal and offspring hearts were homogenized, and $80 \mu \mathrm{g}$ of protein quantified by Bradford assay were loaded each lane for electrophoresis in $0.1 \%$ SDS and $10 \%$ polyacrylamide gel with $4 \%$ stacking gel, and then transferred to immobilon $\mathrm{P}$ polyvinyldifluoride membranes (Millipore, Billerica, MA, USA). Immunoblotting was performed by incubating each membrane in blocking buffer for $1 \mathrm{~h}$, and then incubated in the primary antibodies (Santa Cruz Biotechnology, Santa Cruz, CA, USA) against $\mathrm{AT}_{1} \mathrm{R}$ or $\mathrm{AT}_{2} \mathrm{R}$ (1:500) overnight at $4{ }^{\circ} \mathrm{C}$, respectively. Then the membranes were washed and incubated at room temperature in horseradish peroxidase-conjugated goat antirabbit antibody at 1:5000 dilution. The bound antibody was then visualized by using enhanced chemiluminescence detection (Amersham Biosciences, Piscataway, NJ, USA) and exposure to X-ray film. All samples were normalized to $\beta$ actin as control. For quantification of $\mathrm{AT}_{1} \mathrm{R}$ and $\mathrm{AT}_{2} \mathrm{R}$ protein levels, the photographs were digitalized and analyzed using a scanner. The magnitude of the immunosignal was given as a percentage of the internal control.

\section{Offspring weight and arterial pressure}

Litter culling was based on random selection by computer. Male offspring were weighted at 4 weeks and $7-8$ weeks after birth ( $n=5$, each group, each offspring from different dam). Arterial pressure was recorded directly through vascular catheters in the offspring at 7-8 weeks of age. Under condition of anesthesia

Table 1 Relative gene primers sequence

\begin{tabular}{|c|c|c|c|c|}
\hline \multirow[t]{2}{*}{ GAPDH } & Forward primer & 5'-GCAAGTTCAACGGCACAG-3' & NM-017008 & 140 \\
\hline & Reverse primer & 5'-TACAGCACCTCAGATGACCG-3' & & \\
\hline Angiotensinogen & Reverse primer & 5'-GTAGTAGAGGAGATGAAAGG-3' & & \\
\hline \multirow[t]{2}{*}{$\mathrm{AT}_{1 \mathrm{a}} \mathrm{R}$} & Forward primer & 5'-AACCCTCTGTTCTACGGC-3' & NM-030985 & 194 \\
\hline & Reverse primer & 5'-АССТGTСАСТССАССТСА-3' & & \\
\hline \multirow[t]{2}{*}{$\mathrm{AT}_{2} \mathrm{R}$} & Forward primer & 5'-TGATAATCTCAACGCAACTG-3' & NM-012494 & 221 \\
\hline & Reverse primer & 5'-AAAGGAGTAAGTCAGCCACA-3' & & \\
\hline
\end{tabular}


using ketamine and xylazine, PE-10 tubing was inserted into the femoral artery. The catheters were tunneled under the skin and secured between the scapulas with the free end exiting at the base of the neck. The catheters were filled with heparinized saline $\left(50 \mathrm{U} \mathrm{ml}^{-1}\right)$ and plugged with 23 -gauge obturators. The rats were allowed for 2 days of recovery from surgery before testing. On the testing day, the femoral catheter was connected to a Power-Lab multichannel recorder (AD Instruments, Bella Vista, NSW, Australia). Transducer MLT0380/D (AD Instruments) was used. Calibration was performed following the operation
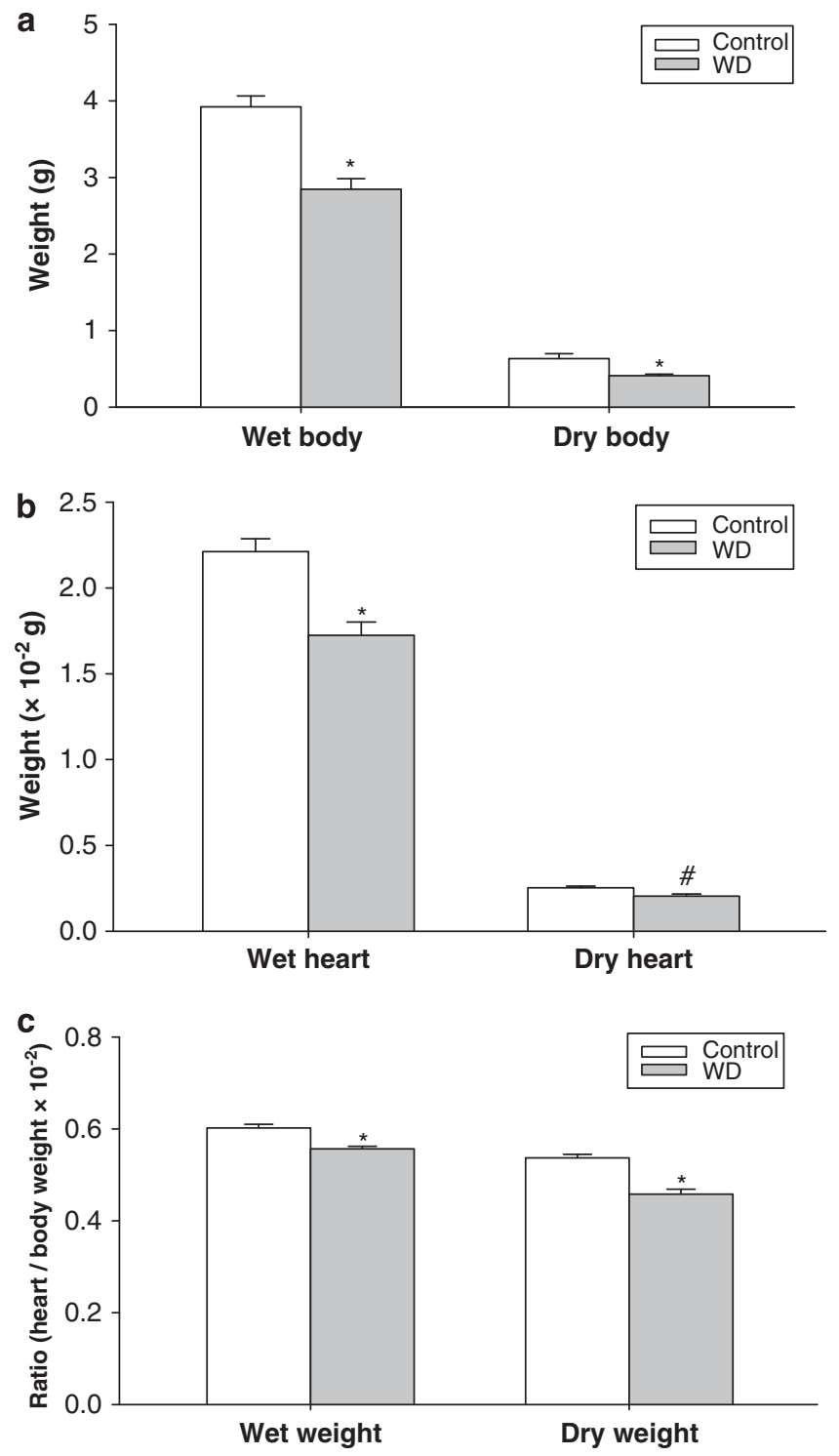

Figure 1 The effect of 3-day maternal water deprivation on fetal body (a) and heart weight (b), and heart/body weight ratio (c). Control, the control group; WD, the water-deprived group. ${ }^{\#} P<0.05 ;{ }^{*} P<0.01$. manual for Powerlab Physiology Record System. Systolic pressure, diastolic pressure, mean arterial pressure and heart rate were recorded directly by using data acquisition software (Powerlab Chart 5, AD Instruments) in unanesthetized and unrestrained rats before and after i.v. administration of Ang II at $100 \mathrm{ng} \mathrm{kg}^{-1}$ in $0.5 \mathrm{ml} 0.9 \% \mathrm{NaCl}$ saline over $2 \mathrm{~min}$. The control rats were administrated with the same volume of the saline. The baroreflex sensitivity was calculated as slope of $\Delta$ pulse interval $/ \Delta$ systolic pressure (in $\mathrm{s} \mathrm{mm}^{-1}$ of mercury) ${ }^{47}$

\section{Data analysis}

Statistical analysis was performed with SPSS software (version 13.0; SPSS Inc., Chicago, IL, USA). A repeated measures of analysis of variance was used to determine difference between the control and the treated groups. Comparison of before and after treatments was determined by a post hoc test. All data are expressed as mean \pm s.e.m., and significance was at $P<0.05$.

\section{RESULTS}

Fetal growth and young offspring weight

Water deprivation did not affect the litter size ${ }^{11-12}$ or the length of gestation (21-22 days). Neonatal survival rate was the same between the control and the experimental groups. Although placental weight and dried placental weight were not changed between the control and WD groups, water deprivation during late gestation significantly decreased fetal body weight, heart weight, dried body and heart weight, and heart/body weight ratio, as well as body and tail length compared with the control group (Figure 1, Table 2).

Body weight of the offspring at 4 weeks after birth in WD group $(57.2 \pm 2.5 \mathrm{~g})$ was significantly lower than that in the control $(69.5 \pm 2.7 \mathrm{~g}, P<0.05)$. However, in young offspring at $7-8$ weeks after birth, there was no significant difference in body weight between the control and the experimental offspring $(267.6 \pm 3.1 \mathrm{vs}$. $270.7 \pm 2.1 \mathrm{~g}, t=0.947, P>0.05)$.

Maternal food intake was not changed on the day 1 of water deprivation. However, it was gradually decreased on the days 2 and 3 during water deprivation, and food consumption on the second and third day was reduced nearly 15 and $25 \%$, compared with the control group (Table 3 ).

\section{Blood values}

Water deprivation during late gestation significantly increased maternal and fetal blood sodium, hematocrit and osmolality. However, maternal water deprivation had no effect on maternal and fetal blood $\mathrm{pH}$ or oxygen saturation (Table 4 ).

\section{Fetal heart ultrastructure}

Prenatal exposure to maternal water deprivation caused ultrastructural alterations in the fetal heart at late gestation (Figure 2). The myocytic mitochondria were swollen with reduced matrix density, altered crystal pattern and vacuolization in the heart tissue. The myofilaments showed irregular patterns.

\section{Plasma hormones}

Compared with the control, water deprivation during pregnancy in rats increased maternal plasma Ang I and Ang II concentrations.

Table 2 The effect of water deprivation on fetal growth (mean \pm s.e.m.)

\begin{tabular}{lccc}
\hline & Placenta weight, $g$ & Dried placenta weight, $g$ & Tail length, cm \\
\hline Control & $0.473 \pm 0.032$ & $0.082 \pm 0.005$ & $1.437 \pm 0.018$ \\
Water-deprived group & $0.442 \pm 0.031$ & $0.081 \pm 0.005$ & $4.181 \pm 0.113$ \\
\hline
\end{tabular}

$$
{ }^{*} P<0.01 \text {. }
$$


The fetal plasma hormones were also significantly increased (Ang I: $4.75 \pm 0.07$ to $5.58 \pm 0.19 \mathrm{ng} \mathrm{ml}^{-1}$; and Ang II: $234.3 \pm 15.2$ to $353.5 \pm 19.9 \mathrm{pg} \mathrm{ml}^{-1}$ ) (Figures $3 \mathrm{a}$ and $\mathrm{b}$ ).

\section{Angiotensinogen mRNA in the fetal liver}

Relative quantitative real-time PCR analysis showed that the angiotensinogen mRNA level in the fetal liver was significantly increased by water deprivation during pregnancy in maternal rats (Figure 4a).

$\mathrm{AT}_{1} \mathrm{R}$ and $\mathrm{AT}_{2} \mathrm{R}$ mRNA and protein in the fetal and offspring heart Both mRNA and protein of $\mathrm{AT}_{1} \mathrm{R}$ and $\mathrm{AT}_{2} \mathrm{R}$ were expressed in the fetal heart. After maternal water deprivation, $\mathrm{AT}_{2} \mathrm{R}$ mRNA levels in the fetal heart were significantly higher than that of the control, although expression of mRNA of $\mathrm{AT}_{1 \mathrm{a}} \mathrm{R}$ and $\mathrm{AT}_{1 \mathrm{~b}} \mathrm{R}$ was the same between the control and WD groups (Figure 4b). In addition, water deprivation during pregnancy significantly elevated $\mathrm{AT}_{2} \mathrm{R}$ protein levels in the fetal heart, whereas $\mathrm{AT}_{1} \mathrm{R}$ protein levels were not changed (Figure $4 \mathrm{c}$ ).

Real-time PCR showed that mRNA of $\mathrm{AT}_{2} \mathrm{R}$ in the heart was significantly increased in the offspring exposure to prenatal water deprivation, whereas $\mathrm{AT}_{1 \mathrm{a}} \mathrm{R}$ and $\mathrm{AT}_{1 \mathrm{~b}} \mathrm{R}$ mRNA were the same between the control and the experimental offsprings (Figure 5). In addition, western blot showed that $\mathrm{AT}_{2} \mathrm{R}$, not $\mathrm{AT}_{1} \mathrm{R}$ protein, was significantly increased in the offspring following prenatal water deprivation (Figure 5).

Cardiovascular responses in the young offspring

Prenatal exposure to maternal water deprivation had no significant influence on systolic pressure $(102.6 \pm 2.7$ vs. $103.0 \pm 2.4 \mathrm{~mm} \mathrm{Hg}$, $t=-0.245, \quad P>0.05)$, diastolic pressure $(86.1 \pm 1.8$ vs. $85.5 \pm$ $2.1 \mathrm{~mm} \mathrm{Hg}, t=0.482, P>0.05)$, mean arterial pressure $(93.8 \pm 2.6 \mathrm{vs}$. $94.4 \pm 1.4 \mathrm{~mm} \mathrm{Hg}, t=-0.484, P>0.05)$ and heart rate $(387.3 \pm 4.5 \mathrm{vs}$. $383.6 \pm 3.5$ b.p.m., $t=0.674, P>0.05)$ during rest periods. However, Ang II-increased systolic pressure, diastolic pressure and mean arterial

Table 3 Maternal daily food intake (mean \pm s.e.m.)

\begin{tabular}{lcc}
\hline & Control & Water-deprived group \\
\hline Water intake, day 1, ml & $17.8 \pm 1.2$ & Water deprived \\
Water intake, day 2, ml & $16.1 \pm 1.0$ & Water deprived \\
Water intake, day 3, ml & $16.8 \pm 1.3$ & Water deprived \\
Food intake, day 1, g & $22.1 \pm 1.1$ & $21.6 \pm 0.8$ \\
Food intake, day 2, g & $21.6 \pm 1.0$ & $18.6 \pm 0.8^{*}$ \\
Food intake, day 3, g & $19.3 \pm 0.8$ & $14.6 \pm 0.6^{*}$ \\
\hline
\end{tabular}

Days 1, 2 and 3: water deprivation or control days 1, 2 and 3.

${ }^{*} P<0.05$ pressure were significantly higher in the offspring exposure to prenatal water deprivation than that in the control (Figures 6a-c). As shown in Figure 7a, Ang II-increased BP caused a decrease of heart rate. Prenatal water deprivation treatment resulted in a
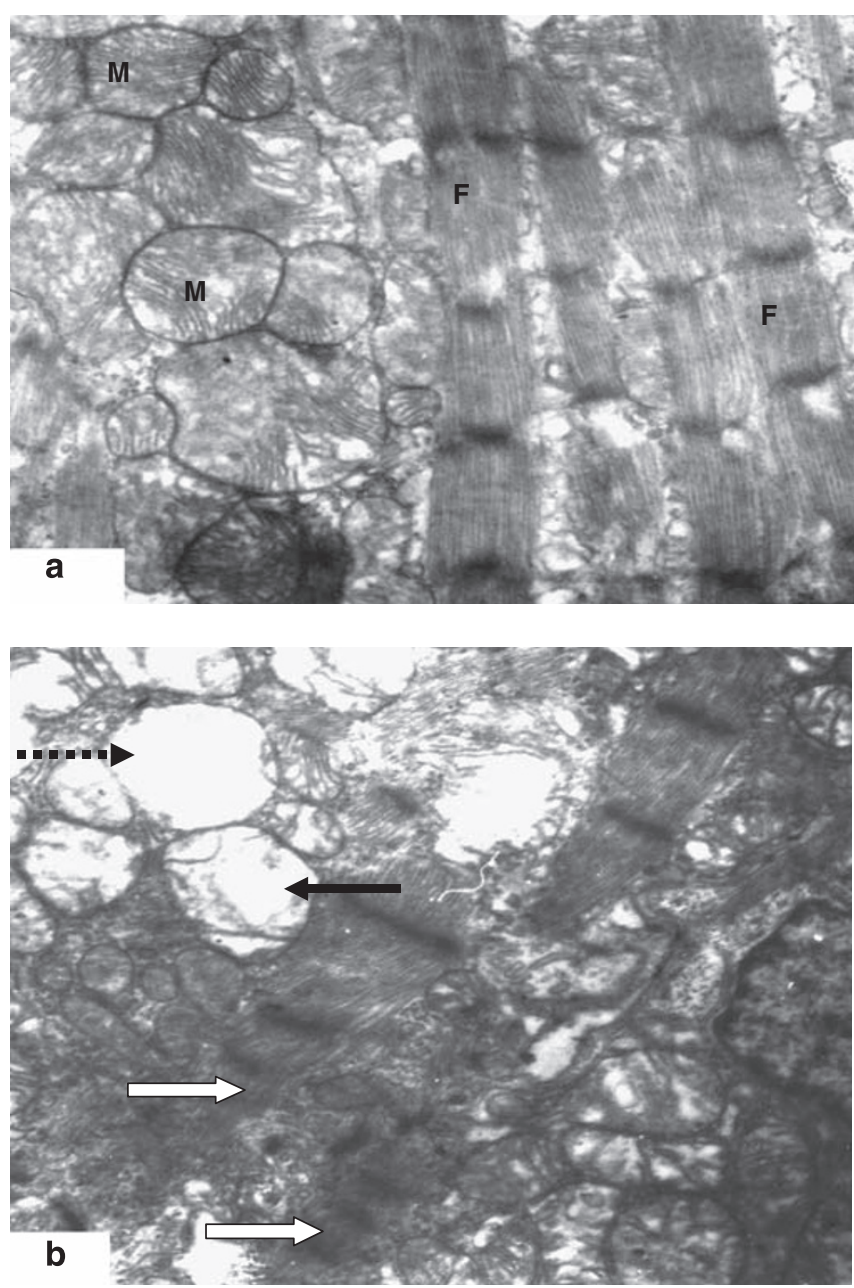

Figure 2 Electron micrograph of myocardium of the fetal rat at gestational day 21 ( $\times 16000)$. (a) The control: the micrograph shows normal myocardium with electron-dense myocytic mitochondria (M) and regular myofilamental pattern (F). (b) Tissue in the water-deprived (WD) group, the myocytic mitochondria are swollen with reduced matrix density, altered crystal pattern (solid arrow) and vacuolization (dotted arrow). The myofilaments show irregular patterns (open arrow).

Table 4 The effect of water deprivation on maternal and fetal arterial blood values (mean \pm s.e.m.)

\begin{tabular}{|c|c|c|c|c|c|}
\hline & $p H$ & $\mathrm{SO}_{2} \%$ & Hct (\%) & $\mathrm{Na}^{+}\left(\mathrm{mmol}^{-1}\right)$ & Osm (mOsm $\left.\mathrm{kg}^{-1}\right)$ \\
\hline \multicolumn{6}{|l|}{ Maternal } \\
\hline Control & $7.44 \pm 0.02$ & $95.70 \pm 2.06$ & $35.33 \pm 0.60$ & $129.10 \pm 0.61$ & $286.71 \pm 2.19$ \\
\hline Water-deprived group & $7.42 \pm 0.02$ & $97.20 \pm 1.88$ & $41.25 \pm 0.86^{*}$ & $139.23 \pm 1.46^{*}$ & $327.64 \pm 4.59 *$ \\
\hline \multicolumn{6}{|l|}{ Fetal } \\
\hline Control & $7.23 \pm 0.01$ & $59.69 \pm 2.91$ & $31.27 \pm 0.87$ & $124.29 \pm 0.76$ & $288.86 \pm 2.43$ \\
\hline Water-deprived group & $7.28 \pm 0.01$ & $63.27 \pm 3.45$ & $34.58 \pm 0.81^{\#}$ & $129.45 \pm 1.26^{*}$ & $324.67 \pm 2.79 *$ \\
\hline
\end{tabular}

Abbreviations: $\mathrm{Hct}$, hematocrit; $\mathrm{Na}^{+}$, sodium; Osm, osmolality; $\mathrm{SO}_{2} \%$, oxygen saturation.

${ }^{\#} P<0.05 ;{ }^{*} P<0.01$. 

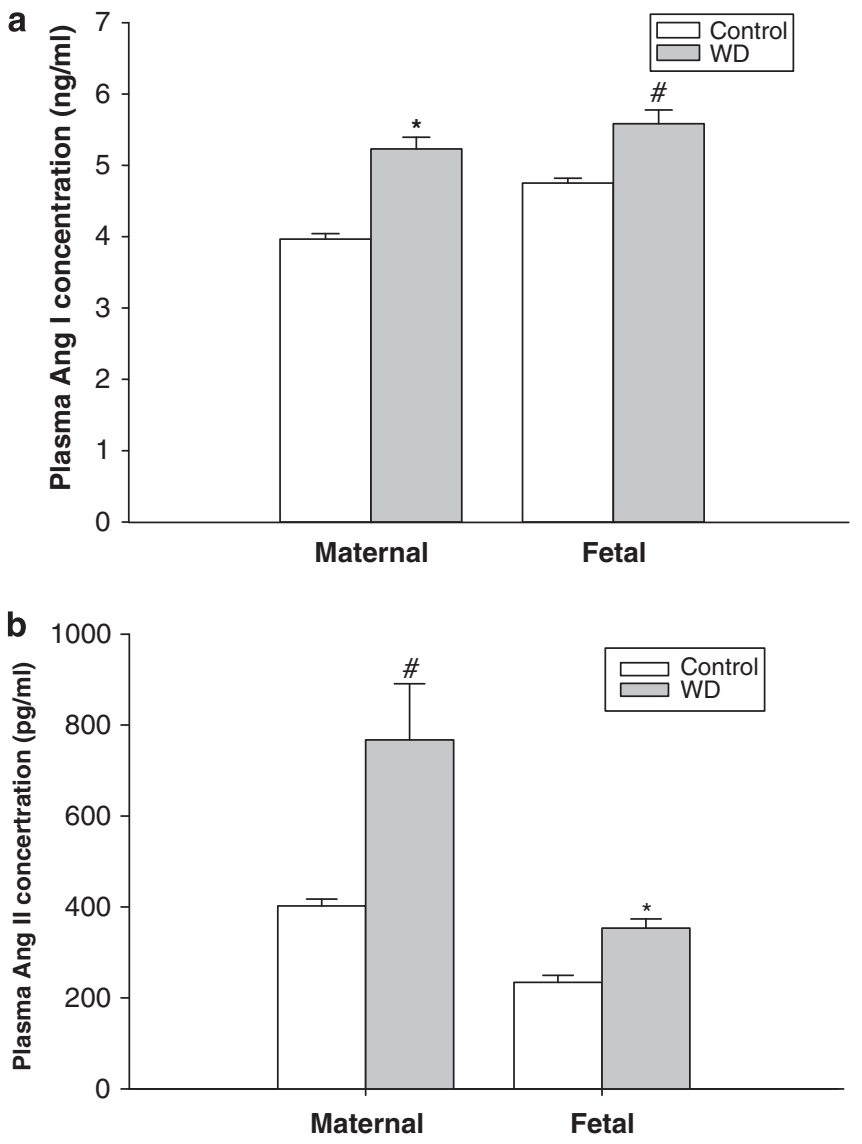

Figure 3 The effect of 3-day water deprivation on the maternal and fetal plasma angiotensin I (a) and angiotensin II (b) concentrations. Control, the control group; WD, the water-deprived group. ${ }^{\#} P<0.05$; ${ }^{*} P<0.01$.

significant decrease in baroreflex sensitivity in the offspring, as compared with the control $\left(0.395 \pm 0.025\right.$ vs. $\left.0.689 \pm 0.137 \mathrm{~s} \mathrm{~mm} \mathrm{Hg}^{-1}\right)$ (Figure $7 \mathrm{~b}$ ).

\section{DISCUSSION}

In this study, water deprivation for 3 days during the late part of pregnancy significantly affected fetal growth and development of RAS in utero. Importantly, those changes in fetal origins were linked to an alternation of cardiovascular responses to Ang II, and changes of the Ang II receptor in the offspring heart.

Water deprivation during pregnancy increased maternal blood sodium, plasma osmolality and hematocrit, consistent with previous studies $^{3,5,25}$ in adult animals. The fetal blood values were also changed, suggesting that dehydration during pregnancy could result in changes in fetal body fluids in utero. Transplacental equilibration probably is a dominant force contributing to water homeostasis in the fetus. ${ }^{26}$

Our results showed in utero growth restriction following maternal dehydration. Considering a relatively higher percentage of body fluids in fetuses than that in adults, we measured fetal body dry weight that was also significantly decreased. In contrast, the placental weight was unchanged. In addition, both fetal body and tail length were reduced, indicating that 3-day water deprivation could induce fetal growth restriction. During 3-day water deprivation, maternal food intake did not change on day 1 , and caused less than $25 \%$ of reduction of food intake at the end of third day of water deprivation. Compared with previous studies that restricted food to $50 \%$ level, and lasted at least
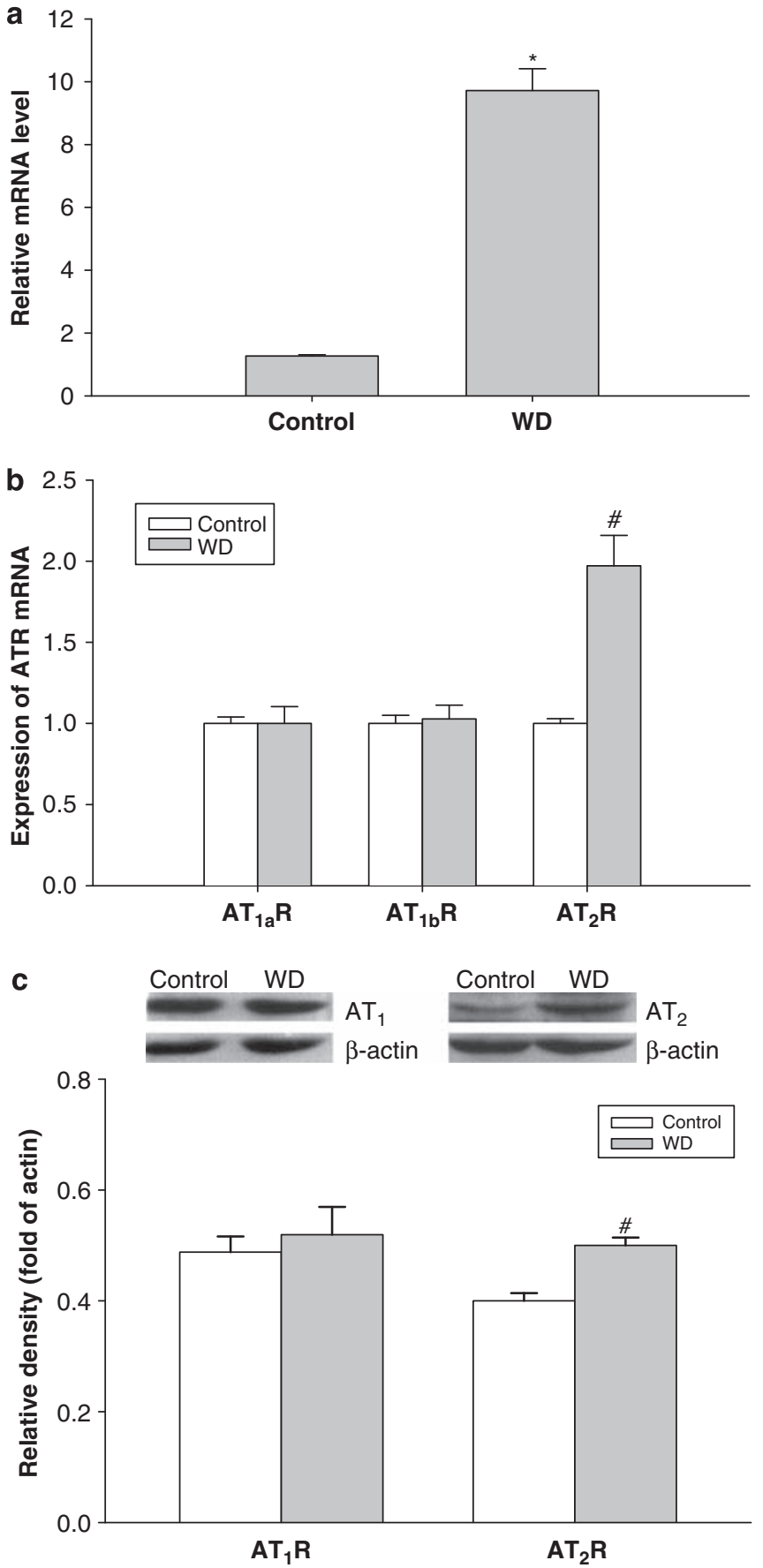

Figure 4 The effect of 3-day maternal water deprivation on angiotensinogen mRNA in the fetal liver (a); angiotensin II receptor mRNA levels in fetal heart (b); and angiotensin II receptor protein in the fetal heart (c). Control, the control group; WD, the water-deprived group. ${ }^{\#} P<0.05$; ${ }^{*} P<0.01$.

10 days or through whole pregnancy, ${ }^{27,28}$ the influence of the limited food reduction in this study was minor. Disease programming in fetal origins are closely linked to low birth weight, and previous studies have shown that mild nutrition restriction during whole pregnancy had little effect on birth weight. ${ }^{29,30}$ Thus, only $25 \%$ reduction of food on the last day of water deprivation was not considered a major cause for the programming in this study.

Both fresh and dry heart weight of the fetus were reduced. It is noteworthy that the electron microscopy showed ultrastructural 

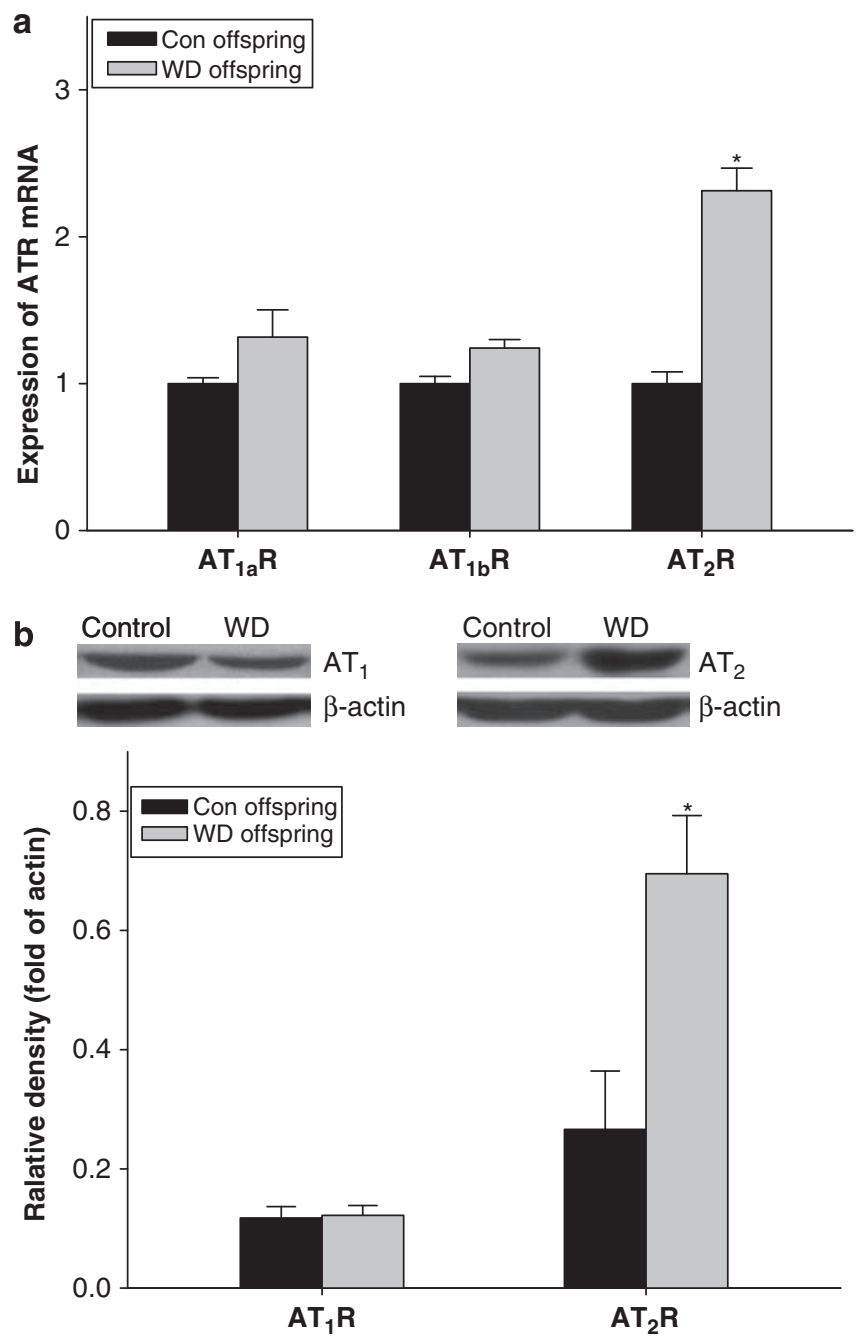

Figure 5 The expression of angiotensin receptor mRNA (a) and protein (b) in the heart of male offspring. Con offspring or control, the control offspring without exposure to prenatal maternal water deprivation; WD offspring, the offspring exposure to prenatal maternal water deprivation. ${ }^{*} P<0.05, n=5$ (each offspring from different litter).

alterations in the heart, including swollen myocytic mitochondria and irregular myofilaments patterns. This indicates that 3-day water deprivation during pregnancy could influence the fetal cardiac development. The fetal RAS was also changed by maternal dehydration. Whether that change may have a role in the alterations of ultrastructure of the fetal heart is worthy of further study.

Although previous studies have shown a significant increase in renin, Ang II and Ang II receptors in dehydrated adult rats, ${ }^{3,8,9,31}$ little was known of the fetal RAS in response to water deprivation during pregnancy. Three day dehydration caused changes of plasma Ang I and Ang II in the maternal rats, which was consistent with previous reports. ${ }^{3}$ What was new in this study was that the fetal plasma Ang I and Ang II were also increased. The placenta is impermeable to polypeptides and protein hormones. ${ }^{32,33}$ Thus, an increase in fetal hormones was independent of the maternal side. New findings of this study include the following: first, the substrate angiotensinogen in the fetal liver, the main source in peripheral systems for the precursor of Ang II, was significantly increased by maternal dehydration; second, an increase in fetal plasma Ang I indicated that either production of
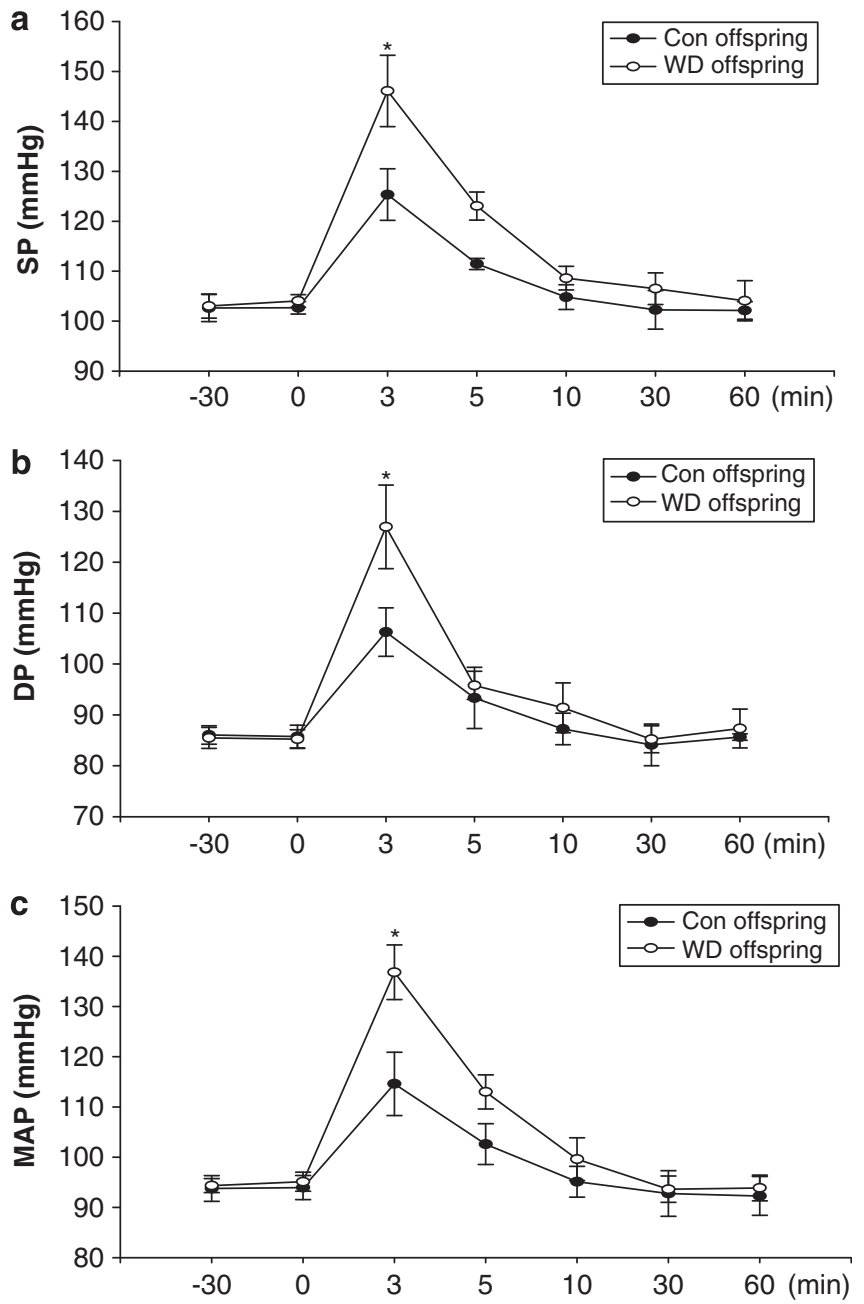

Figure 6 Intravenous angiotensin II-induced responses in systolic, diastolic and mean arterial pressure (SP, DP and MAP) (a, b and $\mathbf{c}$ ) in the young offspring exposed to the maternal dehydration during pregnancy. Control, the control group; WD, the water-deprived group. ${ }^{\#} P<0.05$; ${ }^{*} P<0.01$.

angiotensinogen or activity of a key enzyme renin in the fetus was enhanced; and third, the major bioactive peptide of the RAS-Ang II in the fetal circulation was markedly increased following maternal water deprivation. In addition, we observed a significant increase in the fetal Ang II receptors in the heart. From the substrate to the key enzyme, and from the physiological bio-product to its receptors, the major components of the RAS were affected by water deprivation. ${ }^{34}$ This suggests that the development of the fetal RAS is vulnerable to dehydration. In this study, we focused on Ang during maternal water deprivation, and did not measure other hormones, such as corticosterone, that also may be changed in stress. This should be considered in future studies.

Angiotensin II acts at its subtype receptor, $\mathrm{AT}_{1}$ and $\mathrm{AT}_{2} \cdot{ }^{35}$ Several lines of studies ${ }^{36-38}$ suggested differences in the expression of fetal $\mathrm{AT}_{1}$ and $\mathrm{AT}_{2}$ receptors. In the fetal heart, $\mathrm{AT}_{2}$ receptor expression is low in the early embryonic stages, and rises to high levels during the late embryonic development. ${ }^{38}$ This study showed coexistence of $\mathrm{AT}_{1}$ and $\mathrm{AT}_{2}$ receptors in the fetal heart at late term, and found that cardiac $\mathrm{AT}_{2} \mathrm{R}$ mRNA and protein, not that of $\mathrm{AT}_{1} \mathrm{R}$, were increased after water 

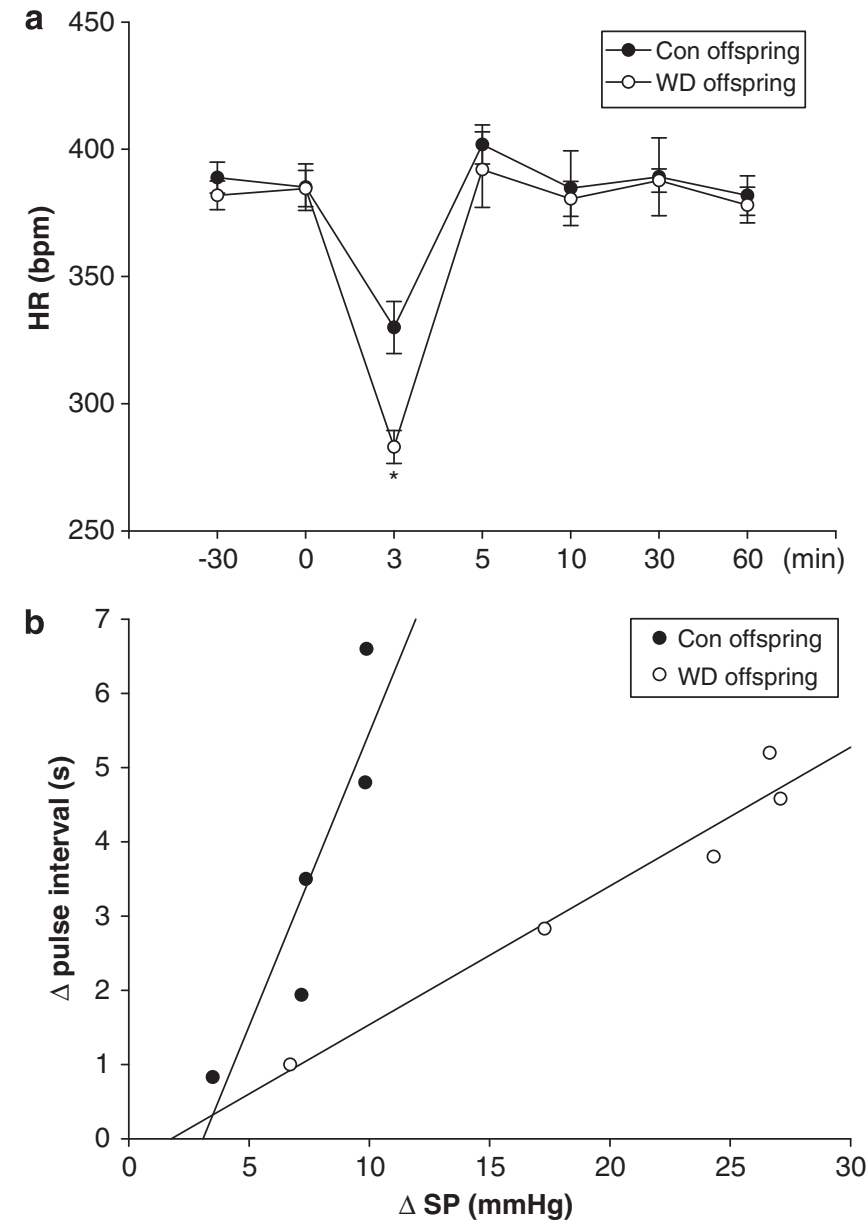

Figure 7 The effect of maternal WD on heart rate (a) and baroreflex sensitivity (b) in the young offspring. Control, the control group; WD, the water-deprived group. ${ }^{*} P<0.01, n=5$ (each offspring from different litter).

deprivation in association with an increase in angiotensinogen, Ang I and Ang II. This finding immediately raised important questions: what would be possible consequences in long-term for the remodeled RAS? Can those changes impact on the cardiovascular system of the offspring?

To address the questions, this study focused on BP and cardiac Ang II receptors in the young offspring 7-8 weeks of age. Interestingly, weight of the young offspring was similar between the control group and the prenatal dehydrated group, indicating a catch-up growth 1 month after birth, as reported before. ${ }^{39,40}$

In the adolescent offspring, there was no significant difference in either BP or heart rate between the control and prenatal dehydrated offspring. However, when the freely moving young offspring rats were challenged with i.v. Ang II, their systolic, diastolic and mean arterial pressure were markedly increased. Substantial epidemiological evidence indicates that intrauterine insults may program the development of cardiovascular diseases in late life. ${ }^{10-16}$ Exposure to an adverse environment in utero could cause structural and physiological alterations, resulting in hypertension, insulin resistance and glucose intolerance after birth. ${ }^{41-43}$ This study demonstrates that prenatal exposure to water deprivation caused an Ang II-increased BP in the offspring at an adolescent stage. Recent studies ${ }^{44,45}$ in humans and animal models showed a link between adverse intrauterine environments and increased risk of hypertension in adulthood. In this study, BP responses to Ang II stimulation were significantly increased, which was associated with a decrease of sensitivity of baroreflex in the offspring exposure to the prenatal insult, indicating impaired protective mechanism in response to acute increase in BP by Ang II, and suggesting an increased susceptibility of elevated BP in the young offspring. It is noteworthy that the studies in other models ${ }^{46,47}$ of fetal programming also showed a decrease in baroreflex functions in the offspring. Causes of hypertension in offspring after exposure to the environmental insults during pregnancy are complicated, the RAS could be one of possible mechanisms for BP changes. The RAS and Ang II receptors have been well demonstrated in response to dehydration. Three day water deprivation could affect the development of $\mathrm{AT}_{1} \mathrm{R} / \mathrm{AT}_{2} \mathrm{R}$ and influence $\mathrm{BP}$ in the offspring.

Furthermore, we found that cardiac mRNA and protein of $\mathrm{AT}_{2} \mathrm{R}$, not $\mathrm{AT}_{1} \mathrm{R}$, were also increased significantly in the offspring exposure to prenatal dehydration. It is well known that $\mathrm{AT}_{2} \mathrm{R}$ is predominant in the fetus, ${ }^{36}$ and decreases after birth. However, in offspring rats exposed to prenatal dehydration, the heart $\mathrm{AT}_{2} \mathrm{R}$ was still maintained as fetal phenotype (a relatively higher level). Whether the persistent change of cardiac $\mathrm{AT}_{2} \mathrm{R}$ in the offspring heart contributed to Ang IImediated cardiovascular responses is worthy of further investigation.

In conclusion, important findings in this study include the following: maternal water deprivation could remodel the fetal RAS, as evidenced by changes of fetal plasma Ang II and the Ang II receptor in the heart. This altered RAS in fetal origin was associated with an increased risk of hypertension in later life, as Ang II-stimulated BP was enhanced and baroreflex activity was decreased in the young offspring. The data provide new information in preventive medicine related to pregnancy, and offer opportunities for further exploring mechanisms of development of cardiovascular diseases in fetal origins.

\section{ACKNOWLEDGEMENTS}

We thank Professor LD Longo for his help. This study was partially supported by HL090920, National Natural Science Foundation (no: 30871400, no: 30973211), Jiangsu Grant (BK2006703, 08KJB320013) and Suzhou Grant (no. 90134602, N2134703, EE134704).

1 Leung PS. The physiology of a local renin-angiotensin system in the pancreas. J Physiol 2007; 580: 31-37.

2 Peach M. Renin-angiotensin system: biochemistry and mechanism of action. Physiol Rev 1977; 57: 313-370.

3 Salas SP, Giacaman A, Vio CP. Renal and hormonal effects of water deprivation in lateterm pregnant rats. Hypertension 2004; 44: 334-339.

4 McKinley MJ, Denton DA, Nelson JF, Weisinger RS. Dehydration induces sodium depletion in rats, rabbits, and sheep. Am J Physiol Regul Integr Comp Physiol 1983; 45: R287-R292.

5 De Luca Jr LA, Xu Z, Schoorlemmer GHM, Thunhorst RL, Beltz TG, Menani JV, Johnson AK. Water deprivation-induced sodium appetite: humoral and cardiovascular mediators and immediate early genes. Am J Physiol Regul Integr Comp Physiol 2002; 282: R552-R559.

6 Deloof S, De Seze C, Montel V, Chatelain A. Effects of water deprivation on atrial natriuretic peptide secretion and density of binding sites in adrenal glands and kidneys of maternal and fetal rats in late gestation. Eur J Endocrinol 1999; 141: 160-168.

7 Gottlieb HB, Ji LL, Jones H, Penny ML, Fleming T, Cunningham JT. Differential effects of water and saline intake on water deprivation-induced c-Fos staining in the rat. $\mathrm{Am} \mathrm{J}$ Physiol Regul Integr Comp Physiol 2006; 290: R1251-R1261.

8 Di Nicolantonio R, Mendelsohn FAO. Plasma renin and angiotensin in dehydrated and rehydrated rats. Am J Physiol 1986; 250: R898-R901.

9 Chatelain D, Montel V, Dickes-Coopman A, Chatelain A, Deloof S. Trophic and steroidogenic effects of water deprivation on the adrenal gland of the adult female rat. Regul Pept 2003; 110: 249-255.

10 Barker DJ, Osmond C, Golding J, Kuh D, Wadsworth ME. Growth in utero, blood pressure in childhood and adult life, and mortality from cardiovascular disease. Br Med J 1989; 298: 564-567.

11 Edwards LJ, McMillen IC. Maternal undernutrition increases arterial blood pressure in the sheep fetus during late gestation. J Physiol 2001; 533: 561-570. 
12 Gilbert JS, Lang AL, Grant AR, Nijland MJ. Maternal nutrient restriction in sheep: hypertension and decreased nephron number in offspring at 9 months of age. J Physiol 2005; 565: 137-147.

13 Vehaskari VM, Aviles DH, Manning J. Prenatal programming of adult hypertension in the rat. Kidney Int 2001; 59: 238-245.

14 Hemmings DG, Williams SJ, Davidge ST. Increased myogenic tone in 7-month-old adult male but not female offspring from rat dams exposed to hypoxia during pregnancy. Am J Physiol Heart Circ Physiol 2005; 289: H674-H682.

15 Alexander BT. Placental insufficiency leads to development of hypertension in growthrestricted offspring. Hypertension 2003; 41: 457-462.

16 Ortiz LA, Quan A, Zarzar F, Weinberg A, Baum M. Prenatal dexamethasone programs hypertension and renal injury in the rat. Hypertension 2003; 41: 328-334.

17 Franco Mdo C, Akamine EH, Di Marco GS, Casarini DE, Fortes ZB, Tostes RC, Carvalho MH, Nigro D. NADPH oxidase and enhanced superoxide generation in intrauterine undernourished rats: involvement of the renin-angiotensin system. Cardiovasc Res 2003; 59: 767-775.

18 Hadoke PW, Lindsay RS, SeckI JR, Walker BR, Kenyon CJ. Altered vascular contractility in adult female rats with hypertension programmed by prenatal glucocorticoid exposure. J Endocrinol 2006; 188: 435-442.

19 Langley-Evans SC, Sherman RC, Welham SJ, Nwagwu MO, Gardner DS, Jackson AA Intrauterine programming of hypertension: the role of the renin-angiotensin system. Biochem Soc Trans 1999; 27: 88-93.

$20 \mathrm{Ji}$ LL, Gottlieb HB, Penny ML, Fleming T, Toney GM, Cunningham JT. Differential effects of water deprivation and rehydration on Fos and FosB/ $\Delta$ FosB staining in the rat brainstem. Exper Neurol 2007; 203: 445-456.

$21 \mathrm{Kim}$ YC, Lee I, Kim SG, Ko SH, Lee MG, Kim SH. Effects of glucose supplementation on the pharmacokinetics of intravenous chlorzoxazone in rats with water deprivation for 72 h. Life Sci 2006; 79: 2179-2186.

22 Mao CP, Guan JC, Yuan X, Miao Y, Zhu H, Chen L, Lv J, Xu F, Liu Y, Hui P, Zhu Y, Xu Z. Got pure blood in fetal rats? Pediatr Hematol Oncol 2007; 24: 457-460.

23 Kuo Y, Lucero L, Michaels J, DeLuca D, Lukas RJ. Differential expression of nicotine acetylcholine receptor subunits in fetal and neonatal mouse thymus. $J$ Neuroimmunol 2002; 130: 140-154.

24 Livak KJ, Schmittgen TD. Analysis of relative gene expression data using real-time quantitative PCR and the $2^{-\Delta \Delta C T}$ method. Methods 2001; 25: 402-408.

25 Makino Y, Minamino N, Kakishita E, Kangawa K, Matsuo H. Natriuretic peptides in water-deprived and in salt-loaded rats. Peptides 1996; 17: 1031-1039.

26 Ross MG, Sherman DJ, Ervin MG, Castro R, Humme J. Maternal dehydration rehydration: fetal plasma and urinary responses. Am J Physiol 1998; 255: E674-E679.

27 Brennan KA, Kaufman S, Reynolds SW, McCook BT, Kan G, Christiaens I, Symonds $\mathrm{ME}$, Olson DM. Differential effects of maternal nutrient restriction through pregnancy on kidney development and later blood pressure control in the resulting offspring. Am J Physiol 2008; 295: R197-R205.

28 Franco MC, Arruda RM, Fortes ZB, de Oliveira SF, Carvalho MH, Tostes RC, Nigro D. Severe nutritional restriction in pregnant rats aggravates hypertension, altered vascular reactivity, and renal development in spontaneously hypertensive rats offspring. J Cardiovasc Pharmacol 2002; 39: 369-377.

29 Otani L, Shirasaka N, Yoshizumi H, Murakami T. The effects of maternal mild protein restriction on stroke incidence and blood pressure in stroke-prone spontaneously hypertensive rats (SHRSP). Biosci Biotechnol Biochem 2004; 68: 488-494.
30 Fiorotto ML, Davis TA, Schoknecht P, Mersmann HJ, Pond WG. Both maternal over- and undernutrition during gestation increase the adiposity of young adult progeny in rats. Obes Res 1995; 3: 131-141.

31 Israel A, Saavedra JM, Plunkett L. Water deprivation upregulates angiotensin II receptors in rat anterior pituitary. Am J Physiol 1985; 248: E264-E267.

32 Katz AI, Lindheimer MD, Mako ME, Rubenstein AH. Peripheral metabolism of insulin, proinsulin, and C-peptide in the pregnant rat. J Clin Invest 1975; 56: 1608-1614.

33 Thomas AL, Jack PM, Manns JG, Nathanielsz PW. Effect of synthetic thyrotrophin releasing hormone on thyrotrophin and prolactin concentractions in the peripheral plasma of the pregnant ewe, lamb fetus and neonatal lamb. Biol Neonate 1975; 26 : 109-116.

34 Mao CP, Lv JX, Zhu H, Zhou Y, Chen R, Feng X, Cui Y, Wang C, Hui P, Xu F, Xu Z. Fetal functional capabilities in response to maternal hypertonicity associated with altered central and peripheral angiotensinogen mRNA in rats. Peptides 2007; 28: 1178-1184.

35 De Gasparo M, Catt KJ, Inagami T, Wright JW, Unger T. International union of pharmacology. XXIII. The angiotensin II receptors. Pharmacol Rev 2000; 52: 415-472.

36 Shanmugam S, Sandberg K. Ontogeny of angiotensin receptors. Cell Biol Inter 1996; 20: 169-176.

37 Hu F, Morrissey P, Yao J, Xu Z. Development of AT1 and AT2 receptors in the ovine fetal brain. Dev Brain Res 2004; 150: 51-61.

38 Robillard JE, Page WV, Mathews MS, Schutte BC, Nuyt AM, Segar JL. Differential gene expression and regulation of renal angiotensin II receptor subtypes (AT1 and AT2) during fetal life in sheep. Pediatr Res 1995; 38: 896-904.

39 Ibanez L, Suarez L, Lopez-Bermejo A, Díaz M, Valls C, de Zegher F. Early development of visceral fat excess after spontaneous catch-up growth in children with low birth weight. J Clin Endoc Metab 2008; 93: 925-928.

40 Marino R, Hegde A, Barnes KM, Schrier L, Emons JA, Nilsson O, Baron J. Catch-up growth after hypothyroidism is caused by delayed growth plate senescence. Endocrinology 2008; 149: 1820-1828.

41 Alexander BT. Fetal programming of hypertension. Am J Physiol Regul Integr Comp Physiol 2006; 290: R1-R10.

42 Bertram CE, Hanson MA. Animal models and programming of the metabolic syndrome. Br Med Bull 2001; 60: 103-121.

43 Bogdarina I, Welham S, King PJ, Burns SP, Clark AJ. Epigenetic modification of the renin-angiotensin system in the fetal programming of hypertension. Circ Res 2007; 100: 520-526.

$44 \mathrm{Li} \mathrm{G}$, Bae S, Zhang L. Effect of prenatal hypoxia on heat stress-mediated cardioprotection in adult rat heart. Am J Physiol Heart Circ Physiol 2004; 286: H1712-H1719.

45 Dodic M, Samuel C, Moritz K, Wintour EM, Morgan J, Grigg L, Wong J. Impaired cardiac functional reserve and left ventricular hypertrophy in adult sheep after prenatal dexamethasone exposure. Circ Res 2001; 89: 623-629.

46 Segar JL, Roghhair RD, Segar EM, Bailey MC, Scholz TD, Lamb FS. Early gestation dexamethasone alters baroreflex and vascular responses in newborn lambs before hypertension. Am J Physiol Regul Integr Comp Physiol 2006; 291: R481-R488.

47 Xiao DL, Xu ZC, Huang XH, Longo LD, Yang S, Zhang L. Prenatal gender-related nicotine exposure increases blood pressure response to angiotensin II in adult offspring. Hypertension 2008; 51: 1239-1247. 